\title{
Evaluations microbiologiques sur le yaourt en rapport avec les temps et les températures de conservation
}

\author{
par \\ G. LUSIANI, P. SALVADORI \\ et \\ B. BIANCHI-SALVADORI
}

\section{INTRODUCTION}

Le yaourt, du lait fermenté dont l'origine remonte au temps jadis, a reçu dans le dernier après-guerre une impulsion considérable, due surtout aux techniques de productions modernes qui en garantissent la parfaite conservation, également sous l'aspect biologique, pendant longtemps.

La caractéristique particulière de ce produit alimentaire est celle de contenir un nombre considérable de ferments lactiques représentés par une association de Lactobacillus bulgaricus et Streptococcus thermophilus.

Sans approfondir les arguments purement diététiques qui exaltent les vertus biologiques de ces micro-organismes, comme décrit par divers auteurs [1], il faut rappeler l'importance du passage de la flore lactique acidifiante à travers l'appareil digestif [2]. D'après ces expériences, il est naturel que ce produit, biologiquement efficient, puisse être administré également avec adjonction d'autres substances comme fruits, sucre, etc., sans du reste diminuer sensiblement la charge microbienne du yaourt.

A notre avis, des adjonctions de produits alimentaires nonlactiques jusqu'à 30 p. 100 ne compromettent pas les caractéristiques biologiques du produit. Il est donc essentiel de souligner l'importance de la survivance abondante de la flore lactique dans le yaourt.

A ce propos on a analysé un nombre congru de yaourts qui se trouvent dans le commerce, dans le but de pouvoir établir la survivance de la flore lactique dans le temps. Naturellement il a été tenu compte aussi des températures de conservation. 
La recherche s'est effectuée non seulement sur des produits normaux, mais également sur des yaourts additionnés de fruits, de sucre et d'éventuels autres produits alimentaires.

\section{METHODES}

Au cours d'une année entière ont été analysés :

a) 160 échantillons de yaourt titrant 1 p. 100 de m.g. (yaourt écrémé).

b) 120 échantillons de yaourt titrant 3,5 p. 100 de m.g. (yaourt normal).

c) 50 échantillons de yaourt titrant 7 p. 100 de m.g. (yaourt double crème).

Des échantillons des mêmes types, conservés en réfrigérateur à $+5^{\circ} \mathrm{C}$, ont été analysés après 7-20-30-40 j.

Des échantillons de yaourt titrant 1 p. 100 de m.g. ont été analysés après 1-2-5-6-7-8-9-12-14-16 $\mathrm{j}$ de conservation soit à $22^{\circ} \mathrm{C}$, soit à $30^{\circ} \mathrm{C}$.

Les mêmes analyses ont été effectuées sur des yaourts avec des fruits et adjonction de sucre, après 7-12-20-40 j de conservation à $+5^{\circ} \mathrm{C}$.

Analyses effectuées :

1) Acidité exprimée en p. 100 d'acide lactique.

2) Numération des lactiques acidifiants au moyen de dilutions successives en lait stérile écrémé, en employant trois tubes par dilution et en retenant le nombre le plus probable selon le tableau de $\mathrm{Mc}$ Crady, avec incubation à $45^{\circ} \mathrm{C}$ durant $24 \mathrm{~h}$.

\section{RESULTATS}

La figure 1 indique les valeurs moyennes d'acidité exprimées en acide lactique, déterminées sur les yaourt du type écrémé, normal et double crème.

Au début, les valeurs d'acidité du yaourt normal se présentent légèrement inférieures à celles du yaourt écrémé, tandis qu'après $20 \mathrm{j}$ ces valeurs s'équivalent. Les augmentations ne sont toutefois pas considérables, aussi parce qu'il est clair que le produit a été conservé au froid. Les valeurs d'acidité du yaourt double crème se maintiennent, logiquement, sur un niveau inférieur.

La figure 2 indique les valeurs d'acidité de yaourt aromatisé avec des fruits; dans ce cas aussi on note de légères variations dans 
Temps de conservation (en jours)

Teneur des yaourts (p.100) en matière grasse

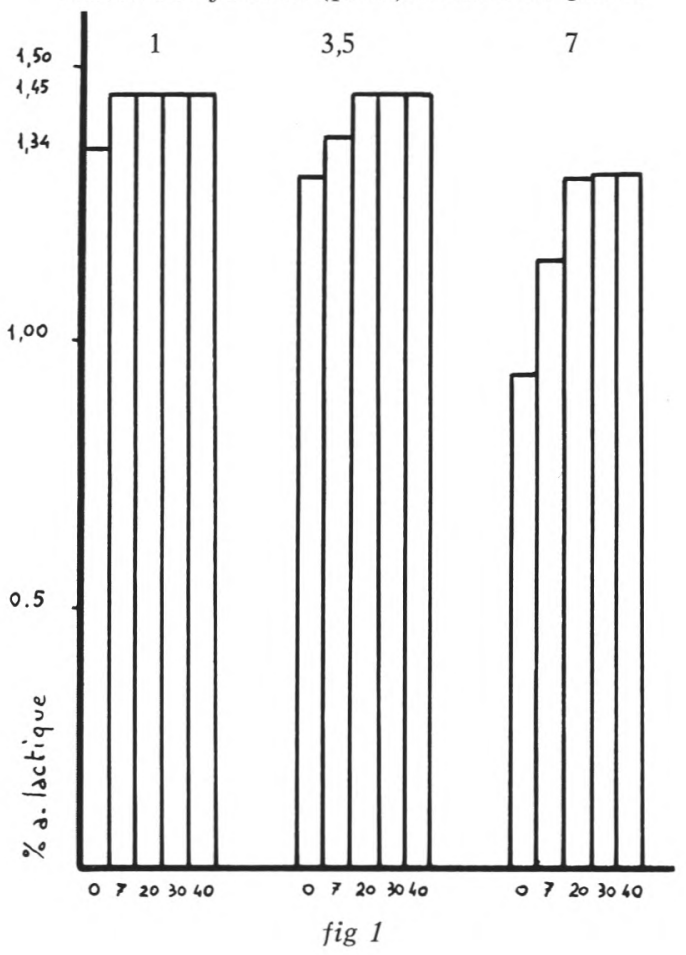

Aromatisation des yaourts :

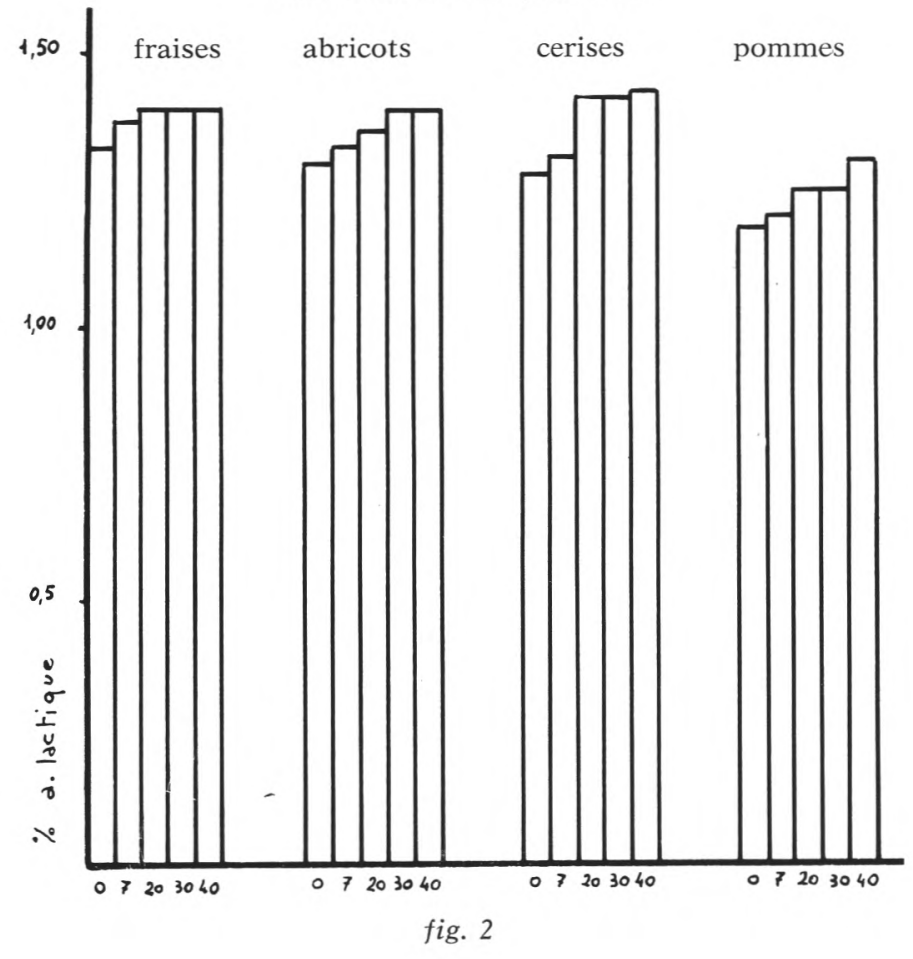

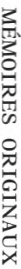



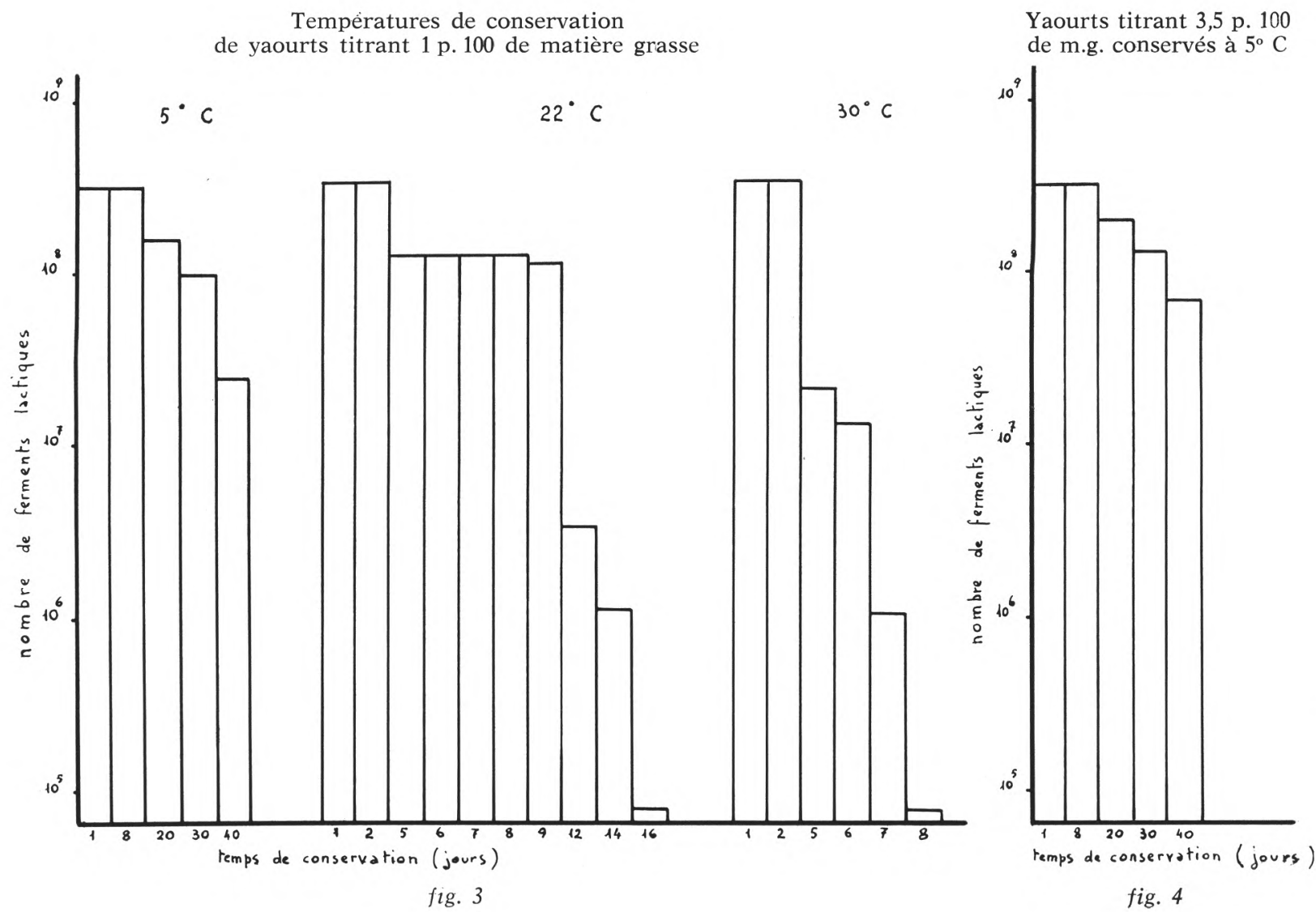

ू

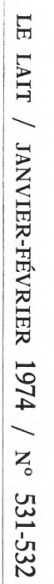


l'augmentation de l'acidité même, laquelle, du reste, ne diffère pas beaucoup de celle du yaourt normal.

La figure 3 montre de manière très évidente comment la flore microbienne lactique acidifiante d'un yaourt atteint des niveaux considérables même après $30 \mathrm{j}$ de conservation (environ 100 millions), tandis qu'après $40 \mathrm{j}$ le nombre des ferments lactiques, tout en étant diminué, est toujours de quelques dizaines de millions.

Dans le même tableau on note la baisse brusque de la flore lactique dans les produits qui ont été maintenus à température ambiante.

La figure 4 rapporte les mêmes résultats que la précédente, mais en se référant au yaourt normal conservé à $+5^{\circ} \mathrm{C}$.

La figure 5 indique les charges microbiennes déterminées dans le temps, des yaourts avec des fruits, conservés à $+5^{\circ} \mathrm{C}$. Les résultats obtenus montrent que même après $40 \mathrm{j}$, dans tous les types de yaourts analysés, la flore microbienne est encore élevée.

\section{DISCUSSION}

Etant admis qu'une des caractéristiques principales d'un bon yaourt est représentée par la présence d'une flore lactique acidifiante abondante, on peut affirmer que même après $30 \mathrm{j}$ de conservation à $+5^{\circ} \mathrm{C}$ le produit maintient encore favorables ses propriétés biologiques.

Cette conservation vaut également pour les produits aromatisés avec des fruits, ce que montrent éloquemment les histogrammes reproduits dans la figure 5 .

L'adjonction de fruits et de sucre ne nuit aucunement aux caractéristiques biologiques du produit, qui, avec raison, peut encore être dénommé yaourt.

En ce qui concerne les caractéristiques organoleptiques, il faut souligner que d'après la figure 1, le degré d'acidité ne s'élève pas sensiblement dans le temps, et, pour cette raison, dans ce cas également, le yaourt est encore attractif après $40 \mathrm{j}$.

\section{Rés u m é}

Les auteurs ont effectué une recherche sur la survivance des ferments lactiques du yaourt en rapport avec les temps de conservation. Les résultats obtenus montrent clairement qu'un yaourt fabriqué selon les règles normales et conservé au froid $\left(+5^{\circ} \mathrm{C}\right)$ contient encore un nombre considérable de ferments lactiques vivants même 


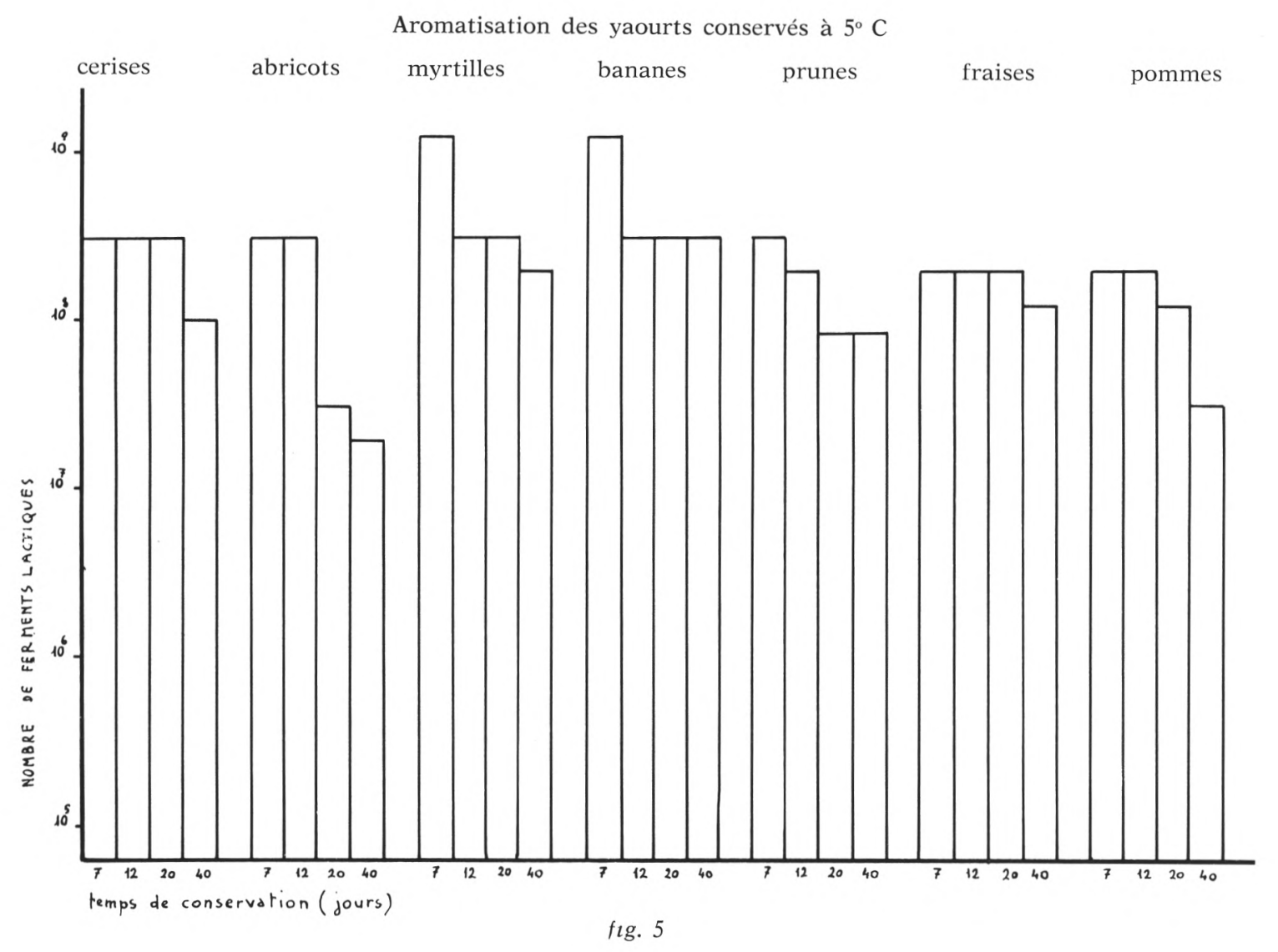

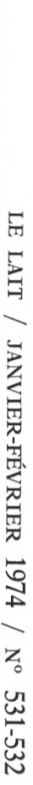


après plus de 1 mois, cela indépendamment du type de yaourt, c'est-à-dire soit écrémé, soit normal, soit avec adjonction de crème ou de fruits.

D'après ces expériences, les fabricants peuvent établir en toute tranquillité (pourvu que la chaîne de froid soit maintenue) un temps de conservation du yaourt d'environ 1 mois.

\section{S u m m a r y}

\section{MICROBIOLOGICAL EVALUATIONS ON YOGHURT IN CONNECTION WITH STORAGE TIMES AND TEMPERATURES}

The authors have carried out a study on the survival of the lactic acid bacteria of yoghurt in connection with storage times. The obtained results show clearly that yoghurt produced according to the normal rules and stored at low temperature $\left(5^{\circ} \mathrm{C}\right)$ still contains a considerable number of living lactic acid bacteria after more than one month from production date ; these results apply to all types of yoghurt, i.e. skimmed and normal as well as cream or fruit added.

According to these experiences, manufacturers may without doubt declare a shelf-life of yoghurt (subject to continuous cold chain) of appr. one month.

\section{Bibliographie}

[1] KaSdoRf (W.), Schmidl (F.). - Yogurt su origen, composicion y valor dietetico. Brossure, Emecé Editores, Buenos Aires.

[2] Salvadori (P.), Bianchi-Salvadori (B.) (1973). - Studio sulle variazioni coprocultorali nell'uomo in rapporto alla somministrazione di yogurt. Convegno sui latti fermentati, Milano 26-2-72, Minerva Dietologica, 8-12, 13. 